American Journal of Pharmacology and Toxicology 6 (1): 27-32, 2011

ISSN 1557-4962

(C) 2011 Science Publications

\title{
Anti-Arthritic Activity of the Methanolic Leaf Extract of Urtica pilulifera L. on Albino Rats
}

\author{
${ }^{1}$ Suha Abudoleh, ${ }^{1}$ Ahmad Disi, ${ }^{2}$ Eyad Qunaibi and ${ }^{3}$ Talal Aburjai \\ ${ }^{1}$ Department of Biological Sciences, Faculty of Science, \\ The University of Jordan, Amman 11942, Jordan \\ ${ }^{2}$ Department of Clinical Pharmacy, Faculty of Pharmacy, \\ Applied Sciences University, Amman 11931, Jordan \\ ${ }^{3}$ Department of Pharmaceutical Sciences, Faculty of Pharmacy, \\ The University of Jordan, Amman 11942, Jordan
}

\begin{abstract}
Problem statement: Urtica pilulifera (Urticeacae) has been used in folk medicine to alleviate inflammation and arthritis. In this study the anti-arthritic effect of methanolic leaf extract of the plant was evaluated and compared to untreated control as well as ibuprofen-treated groups in a rat model of Complete Freund's Adjuvant (CFA)-induced arthritis. Approach: Arthritis was induced by injecting CFA subcutaneously into the right paw. The extract was given orally one day before CFA injection up to the completion of study (for 30 days). Two extract doses $\left(1.33\right.$ and $2.0 \mathrm{~g} \mathrm{~kg}^{-1}$ ) and ibuprofen $\left(53 \mathrm{mg} \mathrm{kg}^{-1}\right)$ as a positive control were used. Paw volume was measured on alternate days up to 30 days. In addition, the effect of the extract on joint deformity, ankle swelling and inflammatory markers was evaluated. Results: The extract prevented arthritis-induced increase in paw volume and joint deformity dose-dependently as compared to control. Moreover, the extract showed significant increase in the packed cell volume [p<0.05]. No alteration of kidney or liver function tests was detected in rats during repeated dose treatment. Conclusion: This study supports the traditional use of $U$. pilulifera for the treatment of inflammatory disorders and rheumatoid arthritis and suggests further evaluation for its role in increasing red blood cells.
\end{abstract}

Key words: Urtica pilulifera, induced arthritis, alleviate inflammation, plant extract, Rheumatoid Arthritis (RA), Complete Freund's Adjuvant (CFA), Erythrocyte Sedimentation Rate (ESR), Rheumatoid Factor (RF), Acute Phase Protein (APP)

\section{INTRODUCTION}

Rheumatoid Arthritis (RA) is one of the most important rheumatic diseases. It is relatively common and its serious forms can cause severe disability. It is a chronic progressive disorder, developing over months or years and involving essentially the synovial joints of the body.

Complete Freund's adjuvant (CFA) contains heatkilled Mycobacteria in a water-in-oil emulsion. After subcutaneous inject ion, CFA induces adjuvant arthritis that can serve as a model to test the anti-arthritic and anti-inflammatory effects of investigational substances. The effect observed in this model seems to be parallel to that observed in human disease (Alluri et al., 2009; Jia et al., 2003; Newbould, 1963; Pearson and Wood, 1959).

The genus Urtica (Urticaeace) contains several alkaloids, flavonoids and isolated compounds such as: kaempferol, isorhamnetin and quercetin, shown to have anti-inflammatory activity (Duke's, 2006). The most extensively studied species of this genus is $U$. dioica, which was shown to have anti-arthritic activity (Riehemann et al., 1999) petroleum ether seed extract of $U$. pilulifera showed a significant antiinflammatory activity against carrageenan-induced acute edema in rats (Kavalali and Tuncel, 1997). This and other species belonging to the same genus have been used extensively by local people in Jordan for treating several diseases such as asthma, anemia, diabetes, kidney and liver infections, renal and gallbladder stones and inflammatory diseases including arthritis. This research was done to be complementary for other studies in this area by examining, in experimental settings, the efficacy of the methanolic leaf extract of $U$. pilulifera against adjuvant-induced arthritis.

Corresponding Author: Suha Abudoleh, Department of Biological Sciences, Faculty of Science, The University of Jordan, Amman 11942, Jordan 


\section{MATERIALS AND METHODS}

Plant material: Urtica pilulifera was collected from Sail Husban, Nauor-Jordan. A voucher specimen was deposited at the herbarium of Biological Sciences Department, University of Jordan (voucher number U.P.81/2006).

Animals: A total of 49 mice $(25-27 \mathrm{~g})$ were used to evaluate acute toxicity of the extract. A total of 48 Sprague Dawley rats weighing $(190-220 \mathrm{~g})$ were used for the rest of experiments. The animals were provided by the animal house, Al-Yarmouk University, Irbid, Jordan. They were kept at conventional conditions of humidity, temperature and light. Food and water were provided ad libitum. All animal procedures were conducted in accordance with Jordanian regulations for animal experimentation and care and approved by the committee of institutional animal care and use.

Animal grouping and extract dilution and application: The rats were divided into six groups of 8 rats each. The methanolic leaf extract was dissolved in normal saline using $10 \%$ tween 20 so as to achieve an oral dose of 1.33 and $2.0 \mathrm{~g} \mathrm{~kg}^{-1}$ body weight for groups 1 and 2, respectively. The extract was administered one day before arthritis induction and daily thereafter for the whole period of experiment ( 30 days). The third group was a positive control group treated with oral ibuprofen at a daily dose of $53 \mathrm{mg} \mathrm{kg}$. The fourth group was a negative untreated control group. The fifth group was also a negative untreated control. However, arthritis was induced in this specific group one month earlier than the other groups and was used exclusively for gross examination of the articular surfaces (see below). The sixth group was a normal non-arthritic group used for comparison with other groups in two experiments only; gross examination of the articular surfaces and evaluation of kidney and liver functions.

Arthritis induction: All Rats were anesthetized by intraperitoneal injection of 5\% chloralhydrate at a dose of $0.25 \mathrm{mg} \mathrm{g}^{-1}$ body weight. Then, to induce arthritis, $0.25 \mathrm{~mL}$ of CFA (Sigma-Aldrech, Germany) was injected into the planter region of the right hind paw of each rat after (Pearson and Wood, 1959).

Measurement of paw volume and ankle diameter: Measurements of the right and left paw volumes were done right before arthritis induction and on alternate days thereafter for 30 days using a plethysmometer (Ugo Basile, Italy, model 7140). Rats were otherwise observed daily. Ankle diameter was determined using a caliper only twice: right before arthritis induction and at the end of the experiment (30 days after arthritis induction).

Gross examination of the articular surfaces: All rats (extract-treated and controls) were sacrificed by overdose of ether 30 days after CFA administration. Right hind limb joints were prepared by removing all the surrounding muscles, capsules and ligaments for gross examination of the articular surfaces of the hip, knee and ankle joints. By this time, arthritis has been induced in the fifth group for two months. The aim of including this group was to evaluate the progression of arthritis and severity of articular damage compared with the other groups. In addition, joints of normal (nonarthritic) untreated rats were prepared for comparison with other groups. To compare the extent of adjuvantinduced arthritis in treatment and control groups, a scoring system for severity of arthritis in rats modified after (Enna et al., 2003) was followed. The scoring system is illustrated in the following Table 1.

Determination of serum inflammatory markers: Leukocyte Count, Packed Cell Volume (PCV), Erythrocyte Sedimentation Rate (ESR), Rheumatoid Factor (RF) and c-reactive protein (CRP) were examined in the serum of the treated and untreated control groups (except groups 5 and 6) 30 days after CFA administration and before sacrifice of the rats.

Determination of safety of the extract: Liver function tests (GPT, GOT) and kidney function tests (serum urea and creatinine concentrations) were determined for the treated and untreated control groups (except groups 5 and 6) 30 days after CFA administration and before sacrifice of the rats to evaluate subacute toxicity of the extract. In addition, acute toxicity was determined by subjecting 7 groups of mice ( 7 mice each) to incremental doses of the extract and determining 24hour lethality.

Statistical analysis: ANOVA test was applied to test the significance of differences between the results of extract-treated and positive and negative control groups. Dunnett's test was used to determine which means differ from negative control group at each point of time. The difference was considered significant at the conventional level of significance $(\mathrm{p}<0.05)$.

Table 1: scoring system for severity of arthritis in rats

\begin{tabular}{ll}
\hline Score & Characteristics of the joint \\
\hline 0 & No changes (normal) \\
1 & Slight redness, roughness and swelling \\
2 & Moderate redness, roughness and swelling \\
3 & Severe redness, swelling and roughness \\
4 & Very severe redness, swelling and roughness \\
\hline
\end{tabular}




\section{RESULTS}

The anti-arthritic activity was evaluated according to the ability of the treatment to inhibit CFA-induced paw swelling, ankle swelling, skin lesions and articular deformity. CFA, administrated subcutaneously in the right paw, caused a significant increase in the volume of not only the right paw, but the left paw as well, with fluctuation in paw volume all over the experimental period (Figs. 1-2, respectively). Significantly, the extract inhibited paw swelling compared with the untreated control dose-dependently in both the right and left paws (Figs. 1-2), which indicates an antiinflammatory effect of the extract. The effect of ibuprofen was intermediate between the high $(2.0 \mathrm{~g}$ $\left.\mathrm{kg}^{-1}\right)$ and low $\left(1.33 \mathrm{~g} \mathrm{~kg}^{-1}\right)$ doses of the extract. All the experimental groups showed a significant increase in the ankle diameter 30 days after CFA administration in comparison with the diameter before the adjuvant administration (Table 1). However, neither treatment was associated with impedance of ankle swelling.

In this investigation, lesions developed at the paws and ankles of untreated rats and were in most cases suppurative, whereas in the extract and ibuprofentreated rats the lesions developed over the paws only and none was suppurative. In addition, functional disability manifested as difficulty in movement and dragging of the paw was observed in most of the control untreated rats, but not in the extract or ibuprofen-treated rats. The disability was accompanied with generalized hardness and darkness of the paws.

Gross examination of the articular surfaces: From gross examination of the articular surfaces of the joints we can conclude that both doses of the extract (1.33 and $2.0 \mathrm{~g} \mathrm{~kg}^{-1}$ ), as well as ibuprofen, were effective in protecting the joints against deformity. The extract effectively inhibited redness, roughness and erosion of the tested joints (ankle, hip and knee) (Fig. 3-7 and Table 2). Although the extract could not inhibit ankle swelling, it did inhibit deformity of its articular surfaces.

Determination of serum inflammatory markers: Both doses of the extract $\left(1.33\right.$ and $\left.2.0 \mathrm{~g} \mathrm{~kg}^{-1}\right)$ caused a significant increase in the PCV compared with untreated control group $(\mathrm{p}<0.05)($ Table 3$)$. There was no significant difference in the erythrocyte sedimentation rates, WBC counts, or CRPs between the treated or control groups at the end of the experimental period. RF was negative in both treated and untreated rats.

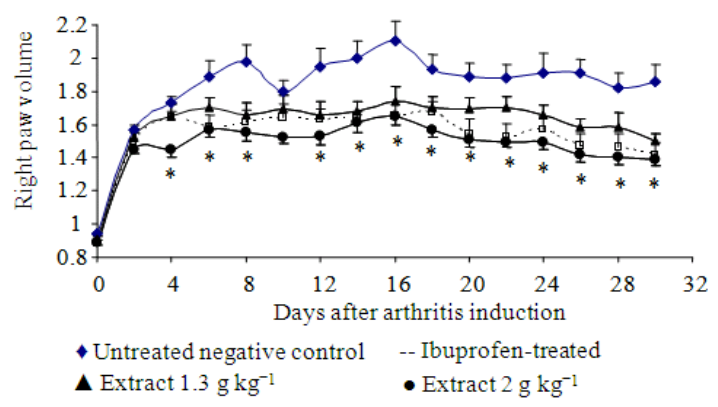

Fig. 1: The methanolic leaf extract of $U$. pilulifera inhibited CFA-induced swelling of right hind paws of rats. Data are expressed as mean \pm SEM $(\mathrm{n}=8)$. Significance $(\mathrm{p}<0.05)$ is shown for the difference between the high dose of the extract $\left(2.0 \mathrm{~g} \mathrm{~kg}^{-1}\right)$ and the untreated control. Zero time is the adjuvant administration

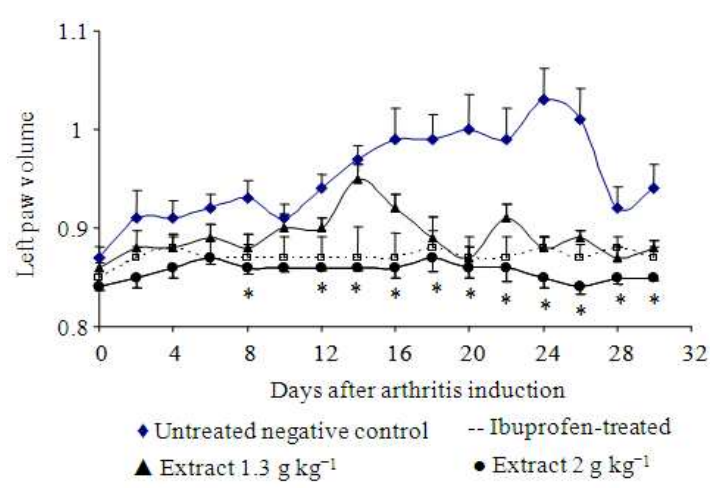

Fig. 2: The methanolic leaf extract of $U$. pilulifera inhibited CFA-induced swelling of left hind paws of rats. Data are expressed as mean \pm SEM $(n=8)$. Significance $(\mathrm{p}<0.05)$ is shown for the difference between the high dose of the extract $\left(2.0 \mathrm{~g} \mathrm{~kg}^{-1}\right)$ and the untreated control. Zero time is the adjuvant administration

Table 2: Ankle diameter in mm (mean \pm SD of 8 rats) of arthritic control rats and rats treated with U. pilulifera or ibuprofen

\begin{tabular}{|c|c|c|c|c|}
\hline Day & $\begin{array}{l}1.33 \mathrm{~g} \mathrm{~kg}^{-1} \\
\text { Extract }\end{array}$ & $\begin{array}{l}2.0 \mathrm{~g} \mathrm{~kg}^{-1} \\
\text { Extract }\end{array}$ & $\begin{array}{l}\text { Untreated } \\
\text { Control }\end{array}$ & $\begin{array}{l}\text { Ibuprofen- } \\
\text { treated }\end{array}$ \\
\hline Zero & $6.0 \pm 0.03$ & $6.0 \pm 0.04$ & $6.1 \pm 0.03$ & $6.0 \pm 0.02$ \\
\hline Thirty & $7.6 \pm 0.04 *$ & $7.4 \pm 0.07 *$ & $7.9 \pm 0.05 *$ & $7.7 \pm 0.05^{*}$ \\
\hline
\end{tabular}

Safety of the extract: In this study the methanolic leaf extract of Urtica pilulifera was shown to be safe in mice, since the highest obtainable oral dose of $23 \mathrm{~g} \mathrm{~kg}^{-1}$ was safe. Table 4 summarize the liver and kidney function tests for rats receiving the extract for 30 days in comparison with normal rats. 
Am. J. Pharm. \& Toxicol., 5 (4): 27-32, 2011

Table 3: Scores of inflammation for joint articular surfaces of arthritic control rats and rats treated with U. pilulifera or ibuprofen

\begin{tabular}{lllllll}
\hline $\begin{array}{l}\text { Articular } \\
\text { surface }\end{array}$ & $1.33 \mathrm{~g} \mathrm{~kg}^{-1}$ & $\begin{array}{l}2.0 \mathrm{~g} \mathrm{~kg}^{-1} \\
\text { Extract }\end{array}$ & $\begin{array}{l}\text { Ibuprofen- } \\
\text { treated }\end{array}$ & $\begin{array}{l}\text { Untreated } \\
\text { Control }\end{array}$ & $\begin{array}{l}\text { Untreated control } \\
\text { with arthritis for 2 months }\end{array}$ & $\begin{array}{l}\text { Normal } \\
\text { non-arthritic }\end{array}$ \\
\hline Talus at Ankle & 1 & 0 & 0 & 2 & 3 & 0 \\
Tibia at Ankle & 0 & 0 & 1 & 1 & 2 & 0 \\
Tibia of femur at hip & 0 & 0 & 0 & 2 & 3 & 0 \\
Femoral condyles at knee & 0 & 2 & 1 & 3 & 2 & 0 \\
Tibial condyles at knee & 0 & 0 & 1 & 2 & 3 & 1 \\
\hline
\end{tabular}

Table 4: PCV values (mean \pm SD of 8 rats) of arthritic control rats and rats treated with $U$. pilulifera or ibuprofen

\begin{tabular}{ll}
\hline Group & PCV (\%) after 30 days \\
\hline Extract $1.33 \mathrm{~g} \mathrm{~kg}^{-1}$ & $46.0 \pm 3.0^{*}$ \\
Extract $2.0 \mathrm{~g} \mathrm{~kg}^{-1}$ & $44.0 \pm 5.1^{*}$ \\
Ibuprofen $\left(53 \mathrm{mg} \mathrm{kg}^{-1}\right)$ & $41.0 \pm 2.7$ \\
Untreated control & $37.0 \pm 5.5$ \\
\hline
\end{tabular}

*: Significantly different $(\mathrm{p}<0.05)$ from untreated control group

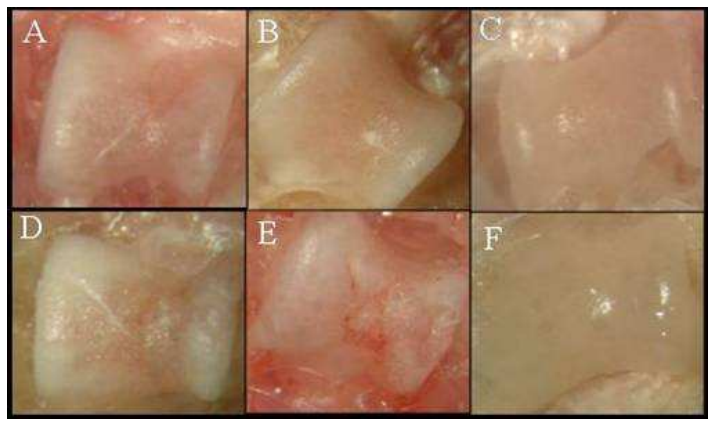

Fig. 3: Representative articular surfaces of the talus at the right ankle joints at the end of the experiment (30 days after CFA administration). (a) rat treated with extract $1.33 \mathrm{~g} \mathrm{~kg}^{-1}$, (b) rat treated with extract $2.0 \mathrm{~g} \mathrm{~kg}^{-1}$, (c) ibuprofentreated rat, (d) untreated control rat, (e) untreated control rat in which arthritis has been induced for two months, (f) normal (nonarthritic) untreated rat which didn't receive CFA

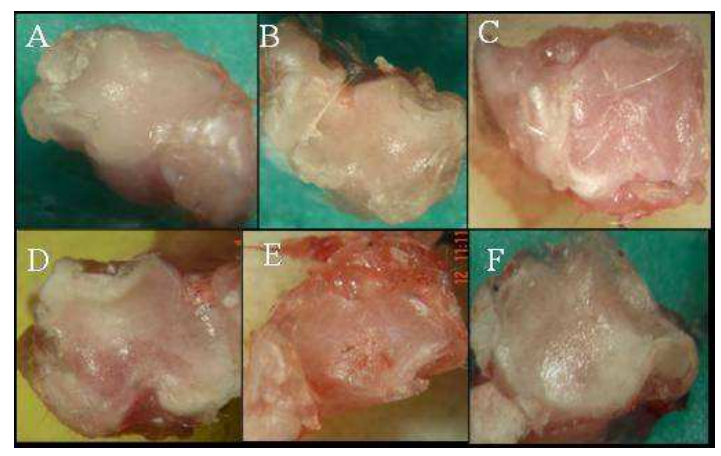

Fig. 4: Representative articular surfaces of the tibia at the right ankle joint at the end of the experiment (30 days after CFA administration). Order is as in Fig. 3

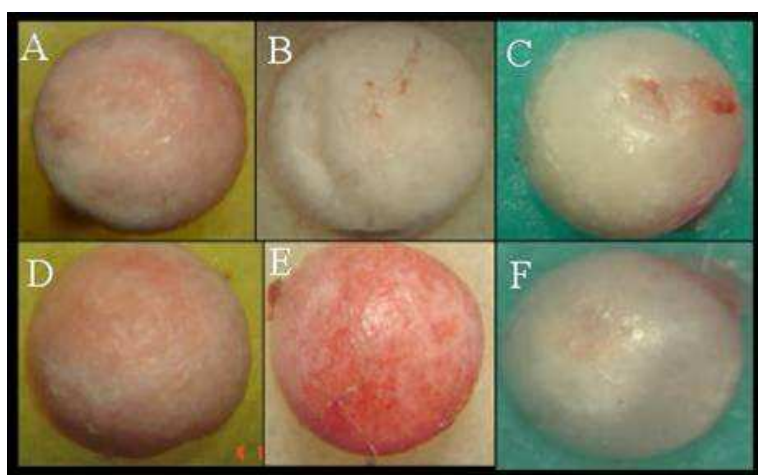

Fig. 5: Representative articular surfaces of the tibia at the femur at the right hip joint at the end of the experiment (30 days after CFA administration). Order is as in Fig 3

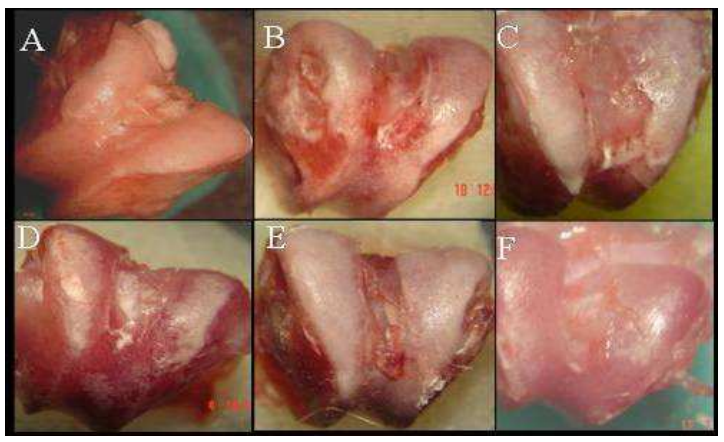

Fig. 6: Representative articular surfaces of the femoral condyles at the knee joints at the end of the experiment (30 days after CFA administration). Order is as in Fig 3

\section{DISCUSSION}

The methanolic leaf extract of Urtica pilulifera is safe at high doses acutely and subacutely. It has significant anti-arthritic effect, as it inhibited the CFA-induced paw swelling, skin lesions and articular deformity. These results support the use of $U$. pilulifera as a herbal medicine for the treatment of inflammatory disorders and rheumatoid arthritis. In addition the extract enhanced PCV, which supports its use in anemic diseases. 


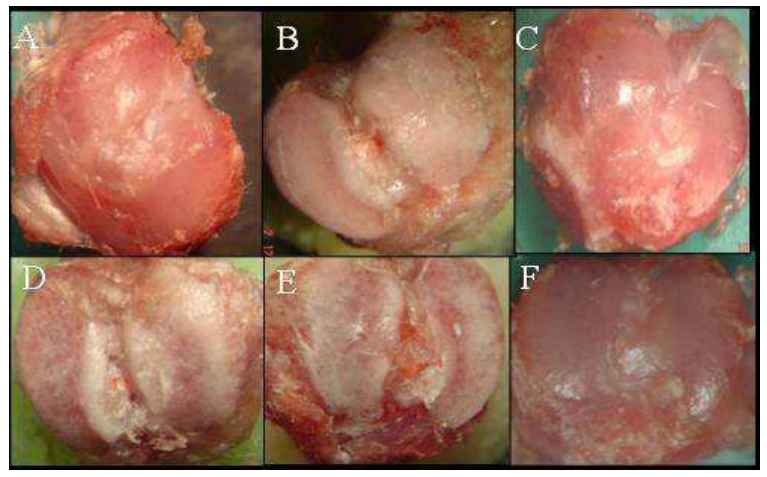

Fig. 7: Representative articular surfaces of the tibial condyles at the knee joints at the end of the experiment (30 days after CFA administration). Order is as in Fig. 3

The results of the paw volume and the transfer of inflammation from the site of CFA administration to the other paw can be explained by a phenomenon that called the migratory phenomenon of the adjuvantinduced arthritis and our result was consistence with findings of (Pearson and Wood, 1959). The fluctuation in paw volume observed in these Figs. 1-2 has also been shown before (Pearson and Wood, 1959) and is an expected phenomenon with inflammatory diseases that frequently exhibit flares and remissions. Newbould (1963) suggested that the process involved in the development of secondary lesion does not appear to be infectious, but rather a generalized immunological response to the constituents of the tubercle bacilli.

Gross examination of the articular surfaces.

The mechanism by which the extract exhibited anti-arthritic activity could be similar to that of $U$. dioica, which was shown to suppress the activation of nuclear factor (NF-kB). In chronic inflammatory diseases, NF-kB is elevated and is responsible for enhanced expression of many pro-inflammatory mediators (Riehemann et al., 1999).

\section{CONCLUSION}

It is worth mentioning that the disease-modifying effects of a variety of non-steroidal anti-inflammatory drugs in rat models (as that observed for ibuprofen in this study) has not been seen in rheumatoid arthritis patients. Some authors suggested that this discrepancy may indicate a greater dependence on prostaglandins for disease development and maintenance in the rat models (Schopf et al., 2006).

Determination of serum inflammatory markers: The result of PCV of treated and untreated rats support the traditional use of Urtica species in folk medicine for the enhancement of hemoglobin concentration. In fact, CRP, the Acute Phase Protein (APP) most commonly followed in human RA patients, is not a major induced APP in the rat and is therefore not as useful as it is in humans (Schopf et al., 2006). RF was negative in both treated and untreated rats, indicating that CFA doesn't induce the formation of immunoglobulins of the rheumatoid factor type.

Safety of the extract: This result indicates that the extract is safer than ibuprofen, for which $\mathrm{LD}_{50}$ is 1.05 $\mathrm{g} \mathrm{kg}^{-1}$ (Budavari et al., 1989). In addition, kidney and liver function tests for the rats receiving the extract daily for 30 days were not significantly different from those of the normal non-arthritic group (group six), indicating safety of the extract on subacute administration.

\section{ACKNOWLEDGMENT}

The researchers are grateful to the Deanship of Academic Research, The University of Jordan for their financial support. Special thanks to Dr. Shtaywy Abdalla for allowing us to use his laboratory facilities.

\section{REFERENCES}

Alluri, V.K., C.B.M. Rao, D. Sundararaju, K. Sengupta and G. Trimurtulu, 2009. Anti-inflammatory activity of Vitex leucoxylon L. bark extracts against Freund's complete adjuvant induced arthritis in Sprague Dawley rat. Am. J. Infect. Dis., 5: 68-73. DOI: 10.3844/ajidsp.2009.68.73

Budavari, S., M. O'Neil, A. Smith and P. Heckeman, 1989. The Merck Index, an Encyclopedia of Chemicals, Drugs and Biological. 14th Edn., Merck and Co. Inc., USA., ISBN-10/ASIN: 091191000X, pp: 2564.

Duke's, 2006. Phytochemical and Ethnobotanical Databases. http://www.ars-grin.gov/cgibin/duke/farmacy2.pl

Enna, S., M. Williams, J. Ferkany, T. Kenakin and R. Porosit, 2003. Models of Inflammation: AdjuvantInduced Arthritis in the Rats. In: Current Protocols in Pharmacology, Unit 5.5. John Wiley and Sons, New York. DOI: 10.1002/0471141755.ph0505s13

Jia, W., W. Gao, N. Cui and P. Xiao, 2003. Antiinflammatory effects of an herbal medicine (XuanJu agent) on carrageenan and adjuvant induced paw edema in rats. J. Ethnopharmacol., 89: 139-141. PMID: 14522445 
Kavalali, G. and H. Tuncel, 1997. Anti-inflammatory activities of Urtica pilulifera. Int. J. Pharmacol., 35: 138-140. DOI: 10.1076/phbi.35.2.138.13286

Newbould, B., 1963. Chemotherapy of arthritis induced in rats by Mycobacterial adjuvant. Br. J. Pharmacol. Chemother., 21: 127-136. PMID: 14066137

Pearson, C. and F. Wood, 1959. Studies of polyarthritis and other lesions induced in rats by injection of mycobacterial adjuvant. I. General clinical and pathological characteristics and some modifying factors. Arthritis Rheumatol., 2: 440-459. DOI: $10.1002 / 1529-0131(195910) 2: 5<440$ :AIDART1780020510>3.0.CO;2-N
Riehemann, K., B. Behnke and K. Osthoff, 1999. Plant extract from stinging nettle (Urtica dioica), an antirheumatic remedy, inhibit the proinflammatory transcription factor NF-kB. FEBS Lett., 442: 8994. PMID: 9923611

Schopf, L.R., K. Anderson and B.D. Jaffee, 2006. Disease Initiation and Pathogenesis. In: Rat Models of Arthritis: Similarities, Differences, Advantages and Disadvantages in the Identification of Novel Therapeutics, Stevenson, C.S., L.A. Marshall and D.W. Douglas (Eds.)., Morgan Jaffee Millennium Pharmaceuticals, Cambridge, MA, USA., pp: 1-34. DOI: 10.1007/978-3-7643-7520-1_1 